MANAGEMENT MODELS AND DIFFERENTIAL AGENCY CHALLENGES ARISING IN AUSTRALIAN MULTI-TITLED TOURISM ACCOMMODATION PROPERTIES

\author{
Kelly CASSIDY \\ and \\ Chris GUILDING \\ Tourism, Sports and Service Innovation Research Centre \\ Griffith University - Gold Coast Campus \\ Queensland \\ AUSTRALIA
}

Corresponding Author:

Professor Chris Guilding

Griffith Business School

Gold Coast campus, Griffith University

QLD 4222, Australia

Phone: + 61755528790

Fax: +61 755528507

Email: c.quilding@griffith.edu.au 


\title{
MANAGEMENT MODELS AND DIFFERENTIAL AGENCY CHALLENGES ARISING IN AUSTRALIAN MULTI-TITLED TOURISM ACCOMMODATION PROPERTIES
}

\begin{abstract}
This paper reports the interview findings of a study designed to appraise differential agency challenges arising between unit owners and resident managers in three distinct types of strata titled tourism accommodation (STTA) operation. The three distinct contexts of STTA management delivery investigated are: 1) management service provision by small independent owner-operators in a single STTA apartment complex, 2) management service provision in strata titled hotels, and 3) management service provision by organisations that manage multiple STTA apartment complexes. Using the four dimensional agency theoretical framework developed by Lambert (2001), it has been found that the potential for agency challenges appear to be greatest in the context of a STTA complex managed by a small independent owner-operator.
\end{abstract}

Keywords: Strata title management, condominium, agency theory. 


\section{MANAGEMENT MODELS AND DIFFERENTIAL AGENCY CHALLENGES ARISING IN AUSTRALIAN MULTI-TITLED TOURISM ACCOMMODATION PROPERTIES}

\subsection{Introduction}

'Strata titling' is the term applied in Australia and New Zealand when referring to real estate that is segregated into separate ownership titles, but the separate titles own some property or infrastructure in common (Ball, 1984). The term "strata title" is used in this paper in a manner synonymous to the way that "condominium" is used in the USA.

This paper reports the findings of a study that probes into agency issues arising in the relationship between unit owners and resident managers in strata title tourism accommodation (STTA) settings. More specifically, the study probes the differential potential for agency dynamics to occur in three distinct forms of STTA management delivery. The theoretical framework for the examination is provided by Lambert's (2001) four item agency conflict model. With respect to the STTA stakeholders identified by Cassidy and Guilding (2010), it appears that the relationship between unit owners and resident managers is the most fundamental to the effective operation of a STTA complex.

STTA appears to be one of the fastest growing tourism accommodation sectors internationally (Pizam, 2006; Warnken, Guilding and Cassidy, 2008). Securing an accurate gauge of this growth is challenging, however, as the actual volume of STTA properties has not been captured well in statistics compiled by tourism authorities or government bodies (Warnken et al, 2008). Although international tourism accommodation statistics that focus on traditional hotels, motels and caravan parks can be found, there is a deficiency of statistics recording the number of holiday second homes or 
a classification of mixed-use buildings that would enable an analysis of tourist vs residential usage to be made. This problem has likely contributed to a volume of research that is startlingly meagre when considered in the light of the large and growing significance of the sector (Cassidy and Guilding, 2010) and also a deficient degree of attention directed to the issue by tourism policy makers.

As noted by Warnken et al (2008), there appear to be multiple reasons accounting for the rapid growth of STTA complexes. From the unit purchaser's perspective, the ostentatious facet of second home ownership has been greatly facilitated by a substantial growth of disposal income over the last quarter of a century. This period has also seen enhanced mobility in connection with leisure pursuits and a move to shorter holiday breaks (Johns and Lynch, 2007). All these developments appear supportive of increased demand for second home ownership. From the tourist's perspective, there appears to be an increase in the demand for accommodation that provides self-catering facilities. This type of accommodation is provided in the STTA model, but is not commonplace in conventional hotels. The STTA model is also appealing to developers as it provides the prospect of selling units 'off the plan', in advance of their construction. This brings forward the timing of property sale cash flow revenue for the developer, signifying a diminution of risk exposure. In addition, by subdividing a large tourism accommodation complex into smaller units of ownership, a developer is accessing a much broader market than is the case if the complex is sold in its entirety to one purchaser. A further factor contributing to STTA growth is the widespread uptake of internet based holiday accommodation bookings. This has eliminated a key competitive advantage enjoyed by those hotel chains that were of sufficient size to maintain sophisticated reservation 
systems prior to mass usage of internet website booking software programs. This range of factors has combined to provide considerable impetus for STTA growth worldwide.

The remainder of the paper is structured as follows. The next section provides literary and theoretical context for the study. The research methodology applied is then described, followed by the findings section. The paper concludes with an interpretation of the study's main findings and an overview of its shortcomings.

\subsection{Literary and theoretical context}

The nascent nature of the STTA literature is evident from the fact that there appears to be no STTA focused study predating 2000. As will be evident from the review presented herein, however, several recent papers have taken an Australian perspective on STTA issues. Cassidy and Guilding (2010) provide an overview of the range of stakeholders involved in STTA. It is notable that two of the three stakeholders that Cassidy and Guilding classify as primary, ie, unit owners and resident managers (RMs), lie as the focus of the study reported herein. ${ }^{1}$ The recency of the STTA literature is evident from the fact that the first STTA academic paper, prepared by Warnken, Russell and Faulkner, was published in 2003. This study can be viewed as a forerunner of the Cassidy and Guilding stakeholder work. In its exploration of destination management challenges arising from rapid STTA growth, it notes the large number of distinct stakeholders involved in STTA complex management relative to players involved in hotel management. The paper also draws out the problem of rejuvenation for destination settings that have a high population of STTA complexes, as well as the need for planning

\footnotetext{
${ }^{1}$ Tourists who stay in STTA complexes constitute the third primary stakeholder group identified by Cassidy and Guilding (2010).
} 
authorities to consider how best to manage the eventual spectre of an aging STTA infrastructure.

Two studies carry particular pertinence for the study reported herein. Firstly, Guilding, Warnken, Ardill and Fredline (2005) took a generic approach in their examination of agency challenges arising in the unit owner / RM relationship. Easthope and Randolph (2009) concur with Guilding et al's view that the relationship is challenging, noting the degree of strain placed on RMs as a result of factors endemic to the relationship. They comment on the saliency of this issue to many large cities such as Sydney, where a high proportion of new units in multi-unit complexes are sold to investors. Cassidy and Guilding’s (forthcoming) formulation of a hierarchically based STTA typology is the second highly pertinent study. Cassidy and Guilding focus much of their attention on three primary generic types that they extract from the broader typology advanced. These three types are: 1) management service provision by small independent owner-operators in a single STTA apartment complex, 2) management service provision in strata titled hotels, and 3) management service provision by organisations that manage multiple STTA apartment complexes. Given the absence of any previous research focusing on differential agency issues arising across distinct STTA management contexts, this basic classificatory scheme appears to constitute an appropriate platform from which to build a context specific analysis of agency challenges arising in the STTA sector. Accordingly, these three STTA contexts provide the basis for the agency analysis reported below.

Cassidy and Guilding (2007) provide an internal management perspective in their examination of price setting practices adopted in Queensland, Australia STTA properties. 
From observations made, Cassidy and Guilding concluded that the pricing strategies are largely intuitive and unsophisticated. A complexity encountered in STTA research concerns the extent to which STTA differences arise across jurisdictional regions. It is notable that in Australia and the USA these jurisdictional regions are not defined by international boundaries, but state boundaries. Everton-Moore, Ardill, Guilding, and Warnken (2006) provide a cross-state analysis of legislative differences applying to strata titled properties in Australia.

A further complexity arising in STTA research concerns the way that holiday properties in large complexes can be seen to lie on a 'part building ownership' continuum that spans the basic timeshare model, fractional timeshares and fully-owned STTA units. STTA's relationship with the basic timeshare model and also fractional timeshares is explored by Warnken and Guilding (2009). While timeshare properties exhibit many key differences from STTA properties (Warnken et al, 2008), there are some facets of the timeshare sector that signify a degree of commonality with particular issues confronted in the STTA sector. For instance, like the STTA sector, most timeshare units will typically have some common property (eg, a lift in a high-rise timeshare complex or an entrance gate and road infrastructure in a horizontally configured timeshare property) and governance arrangements designed to ensure the suitable maintenance of common property in both types of complex have to be developed.

While the timeshare literature cannot be described as large, it is nevertheless more established than the STTA literature. A large part of the timeshare literature has been directed to explicating the timeshare model (eg., Crotts and Ragatz, 2002; Ragatz and Crotts, 2000; Upchurch, 2002) and also distilling factors that account for timeshare's 
rapid growth (eg., Lawton et al, 1998; Upchurch, 2000; Upchurch and Gruber, 2002). It is notable that a particular avenue of timeshare research that focuses on consumer value deriving from timeshare ownership (Crotts and Ragatz, 2002; Sparks et al, 2008) has not been mirrored in the STTA literature. With respect to the study described herein, no study concerned with agency issues arising between timeshare unit owners and managers of timeshare complexes has been found in the literature.

Agency theory focuses on relationships where one party, 'the principal' (frequently represented by a business owner or owners), assigns work to a second party, 'the agent' (frequently represented by an employee of the business owned by the principal). The classic agency relationship involves the principal delegating some decision making authority to the agent (Jensen \& Meckling, 1976; Ross, 1973). Portraying the relationship between RMs and STTA unit owners as a principal-agent exchange (Mills, 1990) appears appropriate, as RMs provide letting and caretaking services to STTA unit owners. The scope of decision making authority typically extended to RMs by STTA unit owners includes the development of a letting marketing strategy, the setting of unit letting rates and also the assignment of units to reservation bookings (Cassidy and Guilding, 2007).

The development of agency theory is often traced back to Berle and Means (1932), although some writers suggest that one can go back to Adam Smith's (1776) The Wealth of Nations. Letza, Sun and Kirkbride (2004) point out that the agency problem was effectively identified by Smith when he argued that company directors were unlikely to be as careful with other peoples’ money as with their own. Subsequently, the firm has been widely viewed as a nexus of contracting relationships between individuals. 
Much of the application of agency theory has evolved through the financial economics literature, with a primary focus on the relationship between managers and shareholders. This focus subsequently broadened into the more general management field with researchers drawing on agency theory to examine organizational behaviour, organizational theory and strategic management aspects (Eisenhardt, 1985, 1988, 1989; Kosnik 1987). Lambert (2001) sees agency theory as constituting one of the most important theoretical paradigms underpinning much accounting research in the 1980s and 1990s. The primary agency theory features that have made it attractive to researchers are its recognition of conflicts of interest, incentive problems and also mechanisms for controlling incentive problems (Bohren, 1998; Eisenhardt, 1989; Lambert, 2001). ${ }^{2}$

Sharma (1997) conceives of agency theory as founded on the triad of agency opportunism, information and risk. The strength of the theory is that it leverages these three fundamental concepts, together with an emphasis on efficiency, to define a problem structure that is inherent to a wide range of business transactions. Eisenhardt notes that the:

'domain of agency theory is relationships that mirror the basic agency structure of a principal and an agent who are engaged in cooperative behaviour, but have differing goals and different attitudes toward risk’ (1989, p.59).

The cornerstone of agency theory is the assumption that the interests of principals and agents diverge and that agents have a propensity to behave opportunistically in a manner that is inconsistent with the interests of principals. Agency theory recognises two

\footnotetext{
${ }^{2}$ Kakabadse and Kakabadse (2001) and Stoney and Winstanley (2001) provide useful critiques of this literature.
} 
distinct costs that a principal can incur when attempting to minimise the possibility of an agent acting opportunistically: (1) monitoring costs and (2) metering costs (Sharma, 1997). The former include all costs resulting from monitoring the behaviour of an agent. If monitoring is impractical, due to prohibitively high costs, a principal will incur metering costs as a result of greater reliance placed on measuring agent action outcomes. The capacity of the principal to manage the potential of an agent acting opportunistically is compromised, however, due to information asymmetry that frequently favours agents and also the potential for the two contracting parties to hold differing attitudes to risk. ${ }^{3}$

\subsection{Research Method}

Exploratory interview data has been collected to enable examination of the issues at hand. In this section, the sample of interviewees are described together with data collection and analysis procedures adopted.

Thirty five semi-structured interviews were conducted and transcribed. These interviews were with 15 industry experts, 10 resident managers and 10 owners. Industry experts are those who have extensive and broad experience in the STTA field. They come from a range of backgrounds and have become known to the research team as a result of the team's on-going STTA research agenda and biennial convenorship of the Strata and Community Title in Australia for the $21^{\text {st }}$ Century conference. Recruitment of the resident managers was assisted by the Queensland Resident Managers Association. Recruitment of the STTA unit owner representatives was facilitated by the Unit Owners Association of Queensland.

\footnotetext{
3 'Information asymmetry' refers to an information access imbalance. It is present where once contracting party can access information that is not available to the second party.
} 
Purposive sampling was undertaken as part of an effort to achieve an Australiawide representation. It should be recognised, however, that due to the Queensland location of a substantial component of the STTA industry, as well as the research team's location, there is an over-representation of interviewees from South East Queensland. It should also be noted that RMs owning management rights businesses do not exist in all Australian states.

An overview of the industry experts (IEs) interviewed is provided in Table 1 . The first column of this table provides an identifying code for each IE (IE1, IE2, etc). The second column of the table records the title or position of the expert and the nature of their expertise (this highlights the breadth of perspectives that the IEs brought to the interviews). The third data column highlights the nature of the business that each IE is involved in. The reference to “Type B" and "Type C' concerns two of the three RM business archetypes elaborated upon in the next section. The table also records the years of STTA experience accumulated by each interviewee and the location of each IE's place of work. Location is depicted by state and the Queensland representatives have been further specified according to Brisbane, Gold Coast, or Sunshine Coast regions.

\section{Insert Table 1 about here}

Table 2 provides an overview of the unit owners interviewed. Unit owners are identified as $\mathrm{O} 1, \mathrm{O} 2$, etc. The location referred to in the table relates to the owner's place of residence. Regional or CBD locations of units within Queensland are detailed. Size of the unit is measured by number of bedrooms. In the 'Total units in complex' column, O3 
has two figures. This results from the owner owning two units in different buildings. O2 and O6 also own two units, however in each instance these are located in the same complex. The type of management refers to one of three organizational forms that operate the complex where the unit is located (to be described in the next section). The table's final column, details the number of years the owner has held the property. More than one figure is reported for those owners owning two units.

\section{Insert Table 2 about here}

Table 3 identifies managers as M1, M2, etc. Location of the complex the managers are operating is broken down into both state and regional or CBD locations. The next three columns detail the total units in the complex, the number of units in the letting pool and a percentage indication of the proportion of units in the letting pool. The subsequent two columns detail the time the manager has worked at his current and previous complexes, with N/A signifying no previous experience in accommodation management. The final column highlights whether the management is a husband and wife team, an employee or a family business.

\section{Insert Table 3 about here}

The interviews had a typical duration ranging between one and two hours. The industry expert and resident manager interviews all took place at the participants' places of work. All unit owner interviews were conducted by phone. Use of an interview protocol for recording information during the interviews assisted in data collection. Clarification of any ambiguous information gathered was achieved by way of email 
correspondence with the participants after their interview. Confirmation or clarification was also achieved by consulting corporate websites and follow up phone calls.

The interview protocol used for data collection was informed by Lambert's (2001) model that identifies four distinct dimensions of conflicting interest arising between principals and agents:

(i) an agent may exert low effort in their work,

(ii) the agent may take an organisation's resources for their private consumption,

(iii) the two parties may have differential time horizons e.g., an agent would be less concerned about future period effects of current actions if he plans to withdraw from the relationship,

(iv) the agent and principal may have differential aversions to risk.

A tailored version of the interview protocol was developed for each of the interviewee sub samples (ie, the industry experts, the unit owners and the resident managers). Interview questions posed were all aligned to one of Lambert's four dimensions of conflict. For example, aligned to Lambert's first dimension of conflict, the RM interview protocol included the following questions: To what extent is there scope for managers in your type of organization to provide a sub-standard performance? and How well can owners gauge the quality of a manager's performance? Aligned to Lambert's second dimension of conflict, the RM interview protocol included the following questions: In this type of organization, to what extent is there an opportunity for the management to divert resources towards their own personal benefit? and How much do you feel this type of activity is occurring in your industry? Aligned to Lambert's third dimension of conflict, the RM interview protocol included the following questions: 
In this type of organization, to what extent is there a tendency for a manager to be more short or long termist than the owners? and To what extent can this difference in time horizons be a problem? Aligned to Lambert's fourth dimension of conflict, the RM interview protocol included the following questions: In this type of organization, to what extent do problems arise as a result of a manager's attitude to risk being different to the average owner's attitude to risk? and Who do you believe is more exposed to risk - you or the unit owners?

As suggested by Miles and Huberman (1994), table shells were utilized as part of the data collection process. To further strengthen the collection phase, interpretive notes were taken throughout the interviews and completed immediately after each interview to minimize loss of insights secured.

Schatzman and Strauss (1973) claim that qualitative data analysis primarily entails classifying things, persons, events and the properties that categorize them. Merriam (1988) and Marshall and Rossman (1999) contend that data collection and analysis will tend to be a simultaneous process in qualitative research. During the analysis period, the data was organized categorically and chronologically and reviewed repeatedly. Identifying and describing patterns and themes from the perspective of the participant(s) and then attempting to understand and explain these patterns and themes has been undertaken, as suggested by Agar (1980). A list of ideas, issues or themes was chronicled, as suggested by Merriam (1988), in the researcher’s field diary.

Lofland (1974) suggests that although data collection and analysis strategies are similar across qualitative methods, the way findings are reported is diverse. Miles and Huberman (1984) address the importance of creating a data display and note that the 
narrative text is the most frequent form of display for qualitative data. The findings are presented in descriptive narrative form in the next section.

\subsection{Findings and discussion}

By way of background, it is important to recognize that the resident management service in Australian and New Zealand STTA properties is typically established as a business by the original STTA complex developer. This business (widely referred to as a 'management rights' business) is sold and provides the purchaser with the right to draw a commission from running the property's letting pool and to draw a salary as compensation for providing maintenance services (Guilding et al, 2005). As noted above, Cassidy and Guilding (forthcoming) identified three distinct forms of management service delivery which they referred to as Types A, B and C. Type A refers to management service provision by small independent owner-operators in a single STTA apartment complex (the owner-operators are typically a husband and wife team). Type B refers to the management service provided in a hotel where the ownership of rooms is strata title based. Type $\mathrm{C}$ refers to management service provision by organisations that manage multiple STTA apartment complexes.

In advance of drawing on Lambert's model to investigate differential agency issues arising across Types A, B and C STTA operations, some key observations concerning broad agency issues arising in the STTA context are provided.

The following comments provided by IE5 highlight the broad and fundamental agency challenge that arises in a STTA setting:

I am getting paid a certain amount of money and my sole perspective is to keep as much money in my pocket as I can. Which means that I need to be driving down service levels or costs in general. You as the owner are paying me a certain 
amount of money but you want me to be driving up service levels from day one so that you can get the best value for money you possibly can. So between manager and owner, we immediately have this conflict. You want one thing, I want another. Here we have this conflict of management rights. I own it and it's my business and I operate it the way I like and if you don't like it, then you can just opt out. I think that is a problem.

O1 provide support for this view in a succinct manner:

They have one goal and that is to make as much money as they can from the owners. The owner's goal is to make as much return as they can.

The extent of this agency challenge can be expected to vary over time in a manner aligned to the economic climate. IE2 observed:

Of course there is a potential conflict and it is fine when the market is fine. When the market turns sour, all the tensions come through.

Lambert's four item agency theory model that was introduced above is drawn upon in the remainder of this section to structure interview observations concerning differential agency challenges arising across Types A, B and C of STTA management service delivery.

\subsection{Effort aversion}

Effort aversion on the part of the agent can be viewed as not exerting an optimal effort when undertaking work, or, more simply stated: 'slacking off'. Interviewees were asked "To what extent is there a potential for management to put in a sub-standard 
performance?'. A specialist hotel consultant with a functional expertise in accounting, IE2, felt that all three management types are subject to medium to high range levels of effort aversion by the agent and drew on a 10 point scale in formulating the following observation:

I think in a strata title structured arrangement, the potential is high in all three cases. The biggest potential, probably the Mum and Dad (Type A), that would be a seven. The branded (Type B) a six and the corporate (Type C) a five. It is a huge problem, I think. The cause of the problem is a lack of scrutiny because of the multiple principal relationship. There is no coordination of vision like there would be in a solo building. With 400 people, like you would have in a strata titled hotel, there is just no one to monitor them and they are only monitored partially as to their own particular interest for wins. So they will monitor the revenues, they might monitor the condition of the building casually, but that is it. They aren't concerned about what is going on inside, so I think there is a huge potential because there is no one watching. The only things that make it different for branded and publicly listed ones is that external groups will motivate a brand recognition and market position, so there is a self-discipline imposed to make sure that the consumers are taken care of because they give a valuation with every visit and the groups will presumably have internal systems to have control over the quality.

These comments together with other observations on the potential for effort aversion across the three generic types, suggest that Types $\mathrm{A}$ and $\mathrm{B}$ have the greatest scope for managerial effort aversion. Consistent with IE2's view, a number of interviewees felt that the additional infrastructure, accountability and reporting procedure 
present in Type C organizations would lessen management effort aversion. IE11 felt, however, that owners' capacity to access useful performance data is a problem for all types:

Mum and Dad and all the others are high risk. It is hard to get any information about how your asset is performing in the marketplace.

M2 commented on an initial high level of effort expended by RMs at the time they first become involved in a STTA complex, and how there is a propensity for this effort to wane with the passage of time. He felt this effort aversion is a result of protracted pressure applied by owners:

You lose the desire at times. We were taking anything we could grab and now we are just saying 'No, we won't do it overnight or that'. You just slow down. We still do the essential, but as for the letting, you slow it off, you do it at your own rate... there is heaps of room for it. If you knock the stuffing out of a manager, he just stops performing because he is so tied up worrying about the little issues that he has to stop doing the job that he should be doing. If you kick the dog for too long, the dog won't get up anymore, and that is happening everywhere.

As a unit investor owner wants a manager's effort to be directed towards maximising the income or returns from units in the letting pool, these owners would like to see the implementation of performance measures directed to this dimension of a manager's work. Many STTA units are resided in by their owners, however. This ownership subset has a predilection to view effective and efficient property maintenance as more important. This highlights a dichotomy of interests between two types of principal in a STTA setting. A managing director of a legal firm with a strata title 
specialisation, IE3, drew on his experience to highlight the way that agency issues can be differentiated on owner occupier vs. investor owner lines:

I am not aware of any dispute where the investor owner is not happy about the standard of maintenance of their building. They have always been about the revenue not being as strong as expected ... The extent of investor-owner unhappiness with the managers is always simply about money. The happiness with owner-occupiers in the same building has been about standard of maintenance and performance.

It is notable that this investor owner vs resident owner issue represents a tension that is not present in Type Bs, as it is rare for an owner of a hotel room to permanently reside in a hotel.

\subsubsection{Type A: effort aversion issues}

IE7 spoke specifically of type As presenting particular problems:

In my experience, the Mums and Dads get very defensive as soon as anyone questions them about anything.

For Types B and C, the management service is provided by an employee of a managing entity. It is only with respect to Type As that the service is provided by an owneroperator. This factor can be expected to result in the Type A manager feeling a greater sense of identity with the business. This greater association with the business likely lies behind IE7's observation that "Mums and Dads" can get very defensive about their running of the business. 
Comments provided by M2 suggest widespread owner dissatisfaction with respect to the value for money provided by Type A managers:

They don't tend to trust you. Probably half of my owners, I don't get any queries from, they have their own businesses and they understand, but the others ... they think I charge them too much.

Comments made by several interviewees suggest that disillusionment is commonplace amongst Type A managers and that this often becomes manifested through effort aversion. One source of the disillusionment concerns a common perception that the purchase of management rights represents a lifestyle choice, a view that can take precedence over a thorough investigation of what the role entails when an individual is making a purchase decision. ${ }^{4}$ The incongruence between the semi-retirement 'lifestyle' in a warmer climate that many Type A managers thought they were purchasing, and the reality of the task appears to be widely felt and frequently profound. IE10 provides insight into the prominence of 'lifestyle choice' that can cloud the exercise of rational judgement when purchasing management rights and contributes to a lack of preparedness for the resident manager position:

I have seen some abysmal Mum and Dad operators and it is very difficult to find good ones because a lot of these guys have been rounding up sheep for themselves. They see it as a lifestyle choice.

\footnotetext{
${ }^{4}$ This lifestyle perception is actively promoted by estate agents that specialise in the sale of management rights.
} 


\subsubsection{Type B: effort aversion issues}

IE 2 saw greater scope for effort aversion to be covert and therefore continue undetected in Type B STTA complexes:

Accountability isn't a problem for the brands because they can shift a lot of cost and underperformance and dress it up pretty.

M5, who worked in a Type B complex, noted that organizational specific factors can affect management accountability to owners:

Well, we don't have any accountability to them as long as we pay the rent. The issue comes when rent is not paid on time. If an operator is unable to meet the rental payment and there is a delay, then obviously that is a concern to the owners. There is nothing that the owners can do about that unless there is fraudulent activity or an ongoing difficulty with paying rent. ${ }^{5}$

\subsubsection{Type C: effort aversion issues}

A couple of comments made about Type Cs relative to Type As are suggestive of a perception that as an organisation, Type Cs will have organisational controls in place to minimise the potential for agent effort aversion. IE1 explains:

In your 'corporates' you have a lot of managers and you've also got a corporate surveillance structure. If he is an employed manager, then he is responsible to his corporate employer as well as to those that are the committee of the owners, so he is under greater surveillance.

M8 supports this view and comments:

\footnotetext{
${ }^{5}$ It was observed that reimbursements made to unit owners were not determined on a consistent basis. Some Type B unit owners earn a commission based on letting rental revenue, while others are paid a fixed rental return for placing their unit in the letting pool in a manner resembling a leasing arrangement. These different forms of owner reimbursement are significant, as the former signifies that some of the risk relating to uncertain returns is born by the unit owner, however, the latter approach signifies that all of the risk over uncertain returns is born by the manager.
} 
That is a big issue. I guess the only way they could question this is if the returns weren't there.

\subsection{Diversion of resources}

The unit owner interviewees were particularly forthcoming with respect to the diversion of resources agency challenge. From comments made, it appears that this challenge is not limited to one type of organizational form. IE 3 commented:

They can all do it if they want to. There is almost no possibility for people to do much about it.

Observations made support Guilding et al’s (2005) view of three moral hazard issues arising in the STTA manager / unit owner relationship. The first concerns the possibility of a resident manager accepting a payment or 'back-hander' in return for placing building sub-contract work with a particular service provider. Comments made by interviewees in this study suggest this type of activity may be widespread, for instance IE7 commented:

I have little faith in unit managers generally. I know the manager at the $X$ (complex name) takes $10 \%$ of tradesmen's costs - kickbacks, dodgy quotes etc, and ensures that the chairman of the body corp's unit is number one for booking. .... Y (Type B) adds an 'administration fee' of $\$ 20$ plus GST to every tradespersons' invoice for work done in our unit - plumbing, electrical, repairs etc.

The second moral hazard example noted by Guilding et al. (2005) concerns the possibility of a resident manager not recording a short term rental of a unit and failing to 
make the appropriate reimbursement to the unit owner. Comments made by this study's interviewees suggest that this practice may be more prevalent in Type As than Types B and $\mathrm{C}$, as accountability systems tend to be more developed in the latter two organizational forms.

The third moral hazard example cited by Guilding et al. (2005) concerns the possibility of a resident manager overstating the cost of maintenance or housekeeping, and keeping the difference between the costs reported to the owner and the payment made to the tradesperson. Several interviewee comments lend support to the existence of such practice.

\subsubsection{Type A: diversion of resources issues}

Type A operators were cited as having the highest potential for diverting resources in a self-interested manner. IE4 commented:

If you have central reservation networks, it has got to be a much lower degree. So Mum and Dads would be the highest rating.

Referring to a Type A STTA complex, O1 expressed concerns suggesting a diversion of resources relating to income and also overstatement of costs:

With the previous managers, we had an income of about \$1,500 per month and under $X$ (new management,) that has dropped to between $\$ 400$ and $\$ 500$. That is a third of the amount, because the managers are taking a great deal more out.... When we bought the unit in Noosa in 2000, on the figures of the previous five years, the management were taking about 25 per cent but we were getting about 75 per cent. It is now down that we get under 60 per cent. Every month there are 
broken glasses and I wouldn't break the amount of glasses in a year that get broken in these units. They replace something at four times the cost that I could buy them at Woolworths and they are buying at wholesale prices. The mark-ups are just ridiculous.

O3 offered a perspective arising from his dealings with several managers:

I can tell you from experience, the managers can be very selective in what they do, and if the people who have the merit to speak up against the actions that they believe are not quite good, they will often find, for one reason or another, which are never ever provable, they don't get much lettings.

\subsubsection{Types B and C: diversion of resources issues}

Managers representing Type B and C operations felt that the greater levels of accountability, transparency and corporate governance procedures apparent in larger organizational structures reduced the possibility of management diverting resources in a self-interested manner relative to the situation in Type As. M9 commented:

There is little scope in our organisation for error. All of our schemes are independently audited and we do that at least once a year, sometimes more. So I think in our form of enterprise it isn't really an issue.

O10 provided a different perspective on the operational aspects of a Type C organization, however. She cited the example of a resort group 'double dipping' with regard to commissions payable by charging a commission through their wholesale arm and a second commission levied by the manager for the same booking. She commented: 
Since it is in X's (a Type C 'Resort Company') interests to rent out units through X's travel agency (owned by the same company) for an extra 30\% commission, there seems to be a straightforward conflict of interest, and our letting agent is not actually looking after our interests.

IE7, an owner of three units in three different complexes, commented on problems observed in Type B and C operations:

At least $50 \%$ of the monthly statements show over-charging of either the manager's commission or maintenance. We have had to point it out to management before we receive a refund. $X$ (Type $C$ company) have been the worst offenders.

The literature provides extensive commentaries on the problems arising from agent opportunism where principals can be seen to be at the mercy of agents (e.g. Bazerman, Neale, Valley, Zaajac \& Kim, 1992; Herman, 1981; Kesner, Shapiro \& Sharma, 1994; Kosnik, 1987; McLaughlin, 1990). Sharma (1997) notes that these problems arise in many commonplace business interactions such as attorney-client, builder-owner and doctor-patient, where more informed agents serve less informed principals. In light of the findings presented here, it appears the STTA owner-manager business relationship can be added to Sharma's (1997) listing of settings where the incidence of agent opportunism appears to be high.

\subsection{Differentials in Time Horizons}

A time horizon differential arises when the envisaged time horizon that either the unit owner or resident manager sees for their STTA involvement departs significantly 
from the time horizon envisaged by the other party with which they are engaged in a STTA property. Overall, it appears that types B and C management entities tend to have longer term time horizons than type A. Because of the amount of unit owners evident in any large STTA complex, the principals have to be viewed as holding a wide range of time horizons. Despite the range of time horizons reflected by unit owners, the consensus view amongst interviewees was that managers should manage a STTA complex with a view to its long term interests. Reflecting this view, M2 commented:

A good manager will look for long-term, certainly owners are there to make money. They want a cheque in the mail every month and they want the return whether it is twelve months or twelve years.

Several industry experts provided comments acknowledging the existence of a time horizon differential. IE3 commented:

I would say that managers have, in general, longer time horizons ... Lot owners will ensure that they can sell it again, so their view will be shorter than that of managers in most cases.

IE2 held a similar view:

You try to optimise profits. Every time the operator spends the owner's money, he is making a decision where you can ask, is he doing it for the owner's good? If he spends $\$ 100,000$ on a new technology system where the benefits might be derived in three years, and the owner is only under a one year ownership arrangement, is the operator acting in the owner's interest? The operator takes a long-term management view. 


\subsubsection{Type A: time horizon differential issues}

IE1 noted that Type A managers tend to be shorter focused than Types B and C:

Mum and Dads usually don't understand the benefits of a longer management contract, while the corporates do.... The corporates are going to be so driven towards a long-term contract because they are businessmen. With Mum and Dads, there can sometimes be an arrangement that is not in their best interest. They mostly have short-term contracts.

From an owner's perspective, IE7 expressed a degree of frustration over the propensity of Type A managers to take a short-term perspective to their STTA involvement:

Mum and Dads are a great concern; we have had 5 managers in 10 years.

It is notable that several interviewee comments concerning type A STTA complexes also highlight concerns over a tendency for a short-termist perspective to be dominant for many owners. M3 commented:

I think some of our owners just want to own their units just for a short time, like make a killing and then leave.

In a similar vein, $\mathrm{O} 1$ stated:

Generally, as an owner you don't really buy for long term. 


\subsubsection{Types B and C: time horizon differential issues}

There was a high consensus view amongst interviewees associated with Types B and C STTA complexes that operators in these complexes are less short-termist than Type A operators. M5 observed:

I have not known of any company that operated on a short term.

M9 agreed:

I think most professional managers are into it long-term. Most owners would be medium term or longer.

IE10, provided an alternate view:

You do get individual operators who want to be out within a two year period and they probably have a bit of a shorter vision on where they are going. Generally this is a pretty tough industry, so I find a lot of unit owners hold their units longer than the managers last.

\subsection{Risk aversion}

Interviewees were asked to comment on the extent to which STTA managers hold different attitudes to risk relative to STTA unit owners. Agency theorists see agents as more risk averse than principals, as agents cannot diversify their employment. A shareholder, acting as the archetypal principal, can achieve diversification through holding a portfolio of investments, however. Guilding et al (2005) note that similar to a company manager situation, small resident managers cannot achieve job diversification, but that they do hold the equivalent of an equity interest in their Type A STTA complex, 
as the value of their investment in the complex will be affected by the complex's letting pool performance. In light of this, a Type A manager is likely to experience heightened risk aversity. In Type B and C operations, however, the managers are generally employees whose attitude to risk is likely to resemble that of a conventionally employed manager.

IE10 elaborated on this issue from a Type A manager's perspective:

The manager's risk will be much higher than the individual unit owner's risk. If I take an apartment in Queensland, an average price in a good location might be $\$ 450,000$. If it is in a building of 50 or 60 apartments, the management rights of that complex is probably worth $\$ 2.5$ million, so you have one individual making a $\$ 450,000$ investment which is backed up by the local property market and the next guy has his investment propped up by his own performance. So there are two factors in it. One, the initial entry price is substantially different and therefore the risk is substantially higher. The second is that when you are buying properties it is underpinned by sales, when you are buying management rights, it is underpinned by performance.

Interviewee comments with respect to whether managers or unit owners have assumed greater risk and which of the two parties is most risk averse appeared to be heavily influenced by the nature of the interviewee's STTA involvement. The unit owners felt that their investment was controlled by the manager and that this exposed them to risk. Conversely, in a manner supportive of IE10's perspective cited above, managers claimed that as their initial investment in the business and the unit complex was more substantial, they bore the greatest risk. 
M2 responded to the question "who takes on the most risk, owners or managers?" in the following way:

I think the manager. The manager has got the biggest investment in the complex. What affects the price of my management rights is how well I am getting people into these units at a good price, so the owner makes good money.

M3 agreed:

I would definitely say us. We have invested in the base and it was our decision and that could backfire if it went the wrong way.

Conversely, O8's following comment is representative of several other unit owners' view on this matter:

I would say that we, as the owners, are more at risk. We rely on their honesty and their ability to manage the complex properly in getting units filled. So that is why I don't use them anymore.

Guilding et al's (2005) conclusion that managers assume greater risk than unit owners was made in the context of Type A STTA complexes. This study's broader scope that incorporates an examination of STTA Types B and C has uncovered a need to extend and qualify Guilding et al's view that STTA managers will be highly risk averse. In the case of Types B and C STTA complexes, there appears little reason to expect that the risk aversity of managers will not converge with that of managers engaged in a conventional employment setting. 


\subsection{Conclusion}

This study has investigated the nature of agency challenges arising between unit owners and managers in three distinct modes of STTA delivery that have been denoted as Types A, B and C. Type A refers to small sole trader resident manager operations that typically involve a husband and wife team operating a single STTA complex. Type B management services are provided in hotels where the ownership of rooms is strata title based. Type $\mathrm{C}$ refers to organisations that purchase the rights to provide resident manager services in multiple STTA apartment complexes. The key contribution of this study derives from the fact that it is the first work to provide a systematic investigation of differential issues arising from distinct modes of STTA management delivery. This focus has not only enabled an advancement to be made on the insights provided by Guilding et al's (2005) more generic study, it has facilitated a deeper understanding of the manner in which contingency factors can result in the manifestation of a range of STTA agency challenges.

A highly summarized version of the study's findings are presented in Table 4 . From this table, it is apparent that agent effort aversion, agent diversion of resources, and differential time horizon agency challenges appear to be most evident in Type A STTA operations. Considered holistically, these observations suggest that Type A STTA complexes will suffer from the greatest agency problems between unit owners and managers. It has also been found that Type A managers are likely to experience the greatest aversion to risk. While the significance of this factor will be dependent on the risk profile of unit owners in a particular building, it appears that the propensity of a Type A manager to experience a high risk aversity points to a further agency challenge in Type A STTA complexes. 
Insert Table 4 about here

The observation that a STTA manager's effort aversion is greatest in Type A was not expected. As they are self employed and stand to personally benefit financially from greater letting revenues generated, one line of a priori reasoning leads to the expectation that Type A STTA managers would exhibit low levels of effort aversion. Despite this reasoning, no interviewee comments supporting this view were noted. In light of this, further research that probes into whether Type A managers exhibit high effort aversion with respect to some dimensions of their work and low effort aversion with respect to other dimensions of their work would likely be revealing. If collecting interview data, we believe it would be insightful to seek interviewee perspectives on the extent to which STTA Type A manager's self-employment situation impacts on their work ethic and motivation. Given this study's observation that managers may exhibit heightened levels of effort aversion following a protracted period of owner criticism, the length of time that a manager has held his position and also the nature of the relationship he experiences with owners could be important contingent factors affecting Type A manager work attitude. It could be that in the presence of high owner animosity, a Type A manager's self employment situation would provide greater scope to act on a desire to limit work effort expended.

While consideration of Table 4 suggests that Types B and C represent forms of STTA delivery characterized by relatively low owner-manager agency challenges, several factors lying beyond the scope of the analysis undertaken here should be born in mind if seeking to formalize a general view on the relative merits of different forms of 
STTA delivery. The relationships that a Type A manager forms with both tourists and unit owners can be expected to be of a more personal nature than those formed by managers in Type B and C complexes. This is because of 'Mum and Dad' operators' closer association and identification with a building where they reside and own a business. Any friendship developments between Type A managers and tourists can be expected to stimulate a higher ratio of returning tourist accommodation bookings. Observations made suggested that unit owners had a greater familiarity with Type A managers than was the case in Types B and C complexes, where relationships tend to be characterised by more of an ephemeral and commercially based nature. While evidence uncovered in this study suggests the closer relationship with Type A managers can, in some situations, lead to greater owner-manager animosity, it would appear short-sighted not to recognize the possibility that in other situations there is considerable scope for a high quality trusting owner-manager relationship to evolve in a Type A complex.

It should be noted that the reported study is limited by the research team's capacity to appraise a manageable number of STTA archetypes, in a meaningful way, through the collection and analysis of qualitative data. The exact form assumed by STTA types can vary across legal jurisdictions due to differing legislative provisions pertaining to STTA complexes. ${ }^{6}$ It is noteworthy that Western Australia (WA) has recently introduced some path-breaking STTA development provisions. Exeter (2009) notes that all new STTA development applications are now referred to Tourism Western Australia for comment. Conditions that are now imposed on most WA STTA development applications include:

\footnotetext{
${ }^{6}$ Consistent with the USA, key strata title legislation in Australia is state (and territory) based.
} 
- Notifications are to be placed on the certificates of title of the proposed lots confirming that the units are to be used for short stay occupancy only.

- Development refurbishment is to be managed by the facility manager on a development-wide basis through the establishment of a refurbishment reserve.

- Upgrading of fixtures, fittings and décor by unit owners is not permitted.

A particularly notable facet of these provisions is the extent to which they have been influenced by tourism policy makers, as opposed to the developer lobby. It is expected that these provisions will greatly ameliorate some major challenges that have compromised the delivery of a quality tourism accommodation service in STTAs. For instance, RMs in new WA STTA complexes will no longer have to manage in a context of competing interests between resident owners and investor owners and they will avoid the challenge of managing a property with inconsistent levels of accommodation refurbishment and décor. These factors signify that the WA STTA model is deserving of research attention, as it augurs well for improved sustainability of a quality STTA service delivery.

While the significance of this study draws primarily from its illustration of differential agency conflicts arising in business transactions between managers and shareholders, the study has a much wider significance in promoting understanding of some key contemporary dynamics in tourism/urban development and destination management. A particular tourism destination challenge associated with the STTA form of tourism accommodation delivery (most notably in Types A and C), when compared to conventional hotels, relates to an absence of any contribution by STTA complexes to the tourism equity of a destination. By 'tourism equity' we mean the provision of nonaccommodation related infrastructure that adds value to the tourism experience of 
destination visitors. Many hotels offer attractions such as restaurants, bars, aesthetically appealing foyer areas and night club entertainment. Any visitor to a destination can indulge in such hotel service provision, regardless of whether they are a registered hotel guest. The same cannot be said for most STTA complexes. Not only is such tourism equity infrastructure lacking in STTA complexes, in many cases a non-resident cannot access the common property of a STTA complex due to swipe card access arrangements. Given the growth of STTA, the dearth of tourism equity infrastructure provided by most STTA complexes can be expected to represent an increasingly challenging issue for tourism destination policy makers.

This study suffers from all the shortcomings generally associated with qualitative research that include scope for subjectivity in data analysis and the possibility of researcher bias being manifest in the collection and analysis of data. In addition, it could be argued that the three archetypal forms of STTA delivery that have been examined can be criticized for being under-defined. For instance, STTA Type B could be broken into two categories comprising branded and non-branded hotels. Further, the Type C classification could be further sub-divided into publically traded management rights operators and private entity management rights operators. It is notable, however, that such shortcomings are bound to be present in any analysis that is based on a classification of organization types, as no classification basis is completely robust. It should also be recognized that an attempt to classify STTA enterprise types into more than three subcategories would have reduced the differences across the STTA types investigated, thereby rendering the observations made in the study more opaque. 
In terms of further research into the STTA phenomenon, a promising line of enquiry offering a high propensity to build on the study reported herein would be to investigate the role and significance of the locus of power between STTA unit owners and resident managers. It is notable that when Type A resident managers purchase management rights in Queensland, they are required to obtain a licence enabling them to operate a trust fund, but their right to manage properties is limited to that complex where they have purchased the management rights. STTA unit owners, however, have the right to choose whoever they wish to act as letting agent for their property, as the resident manager does not have a letting contract for a building, merely an authorisation to operate a letting business (Anderson, 2007). In terms of the power balance between STTA unit owner and resident manager, this suggests one instance of a power imbalance favouring the unit owner. This power imbalance is not as much in evidence for Type C management operators, due to their ownership of management rights in several properties. Other dimensions of power imbalance concern the unit owner's option to fundamentally change the status of their investment by electing to reside in their unit, ie, remove it from the letting pool (a resident manager is unable to make such a radical change in the nature of their investment), and also the much larger investment made by the purchaser of a management rights' business relative to the investment made by a STTA unit owner. The extensive management literature on power provides conceptual frameworks that could be drawn upon if seeking to further theorise on the nature and significance of power in STTA manager / unit owner relationships (see Mizruchi \& Yoo, 2002; Keltner, Gruenfeld, \& Anderson, 2003).

The growing significance of STTA properties in the international tourism landscape signifies that there is a continuing fundamental need to further advance our 
understanding of the phenomenon through research. A consideration of the relativity of the volume of hotels worldwide to the amount of hotel management research reported in the literature, highlights the extent to which the worldwide growth of STTA properties has radically outstripped the quantum of research attention directed to STTA issues. Acknowledging this issue and securing a better understanding of how sustainable STTA development can be achieved would be beneficial for the myriad of STTA stakeholders who include tourists, investors, STTA managers, government, industry and academe. It is hoped that this study will provide a platform to stimulate debate, discussion and further research in the STTA field. 


\section{Reference List}

Anderson, J. (2007) "Management Rights: Public vs private ownership - What is sustainable?” paper presented at the Strata and Community Title in Australia for the $21^{\text {st }}$ Century 2007 conference.

Agar, M. (1980). Stories, Background Knowledge and Themes: Problems in the Analysis of Life History Narrative. American Ethnologist, 7 (2), 223-239.

Anderson, J. (2007). Management Rights: Public vs private ownership - What is sustainable? paper presented at the Strata and Community Title in Australia for the $21^{\text {st }}$ Century 2007 conference.

Ball R. (1984). What is a Strata Title? Law Institute Journal, August, 924-925.

Bazerman, M.H., Neale, M.A., Valley, K.L., Zajac, E.J., \& Kim, Y.M. (1992). The effects of agents and mediators on negotiation outcomes. Organizational Behavior and Human Decision Processes, 53, 55-73.

Berle, A.A., \& Means, C.G. (1932). The Modern Corporation and Private Property. New York: Macmillan.

Bohren, O., (1998). The agent's ethics in the principle-agent model, Journal of Business Ethics, 17(7), 745-755.

Cassidy, K. \& Guilding, C. (Forthcoming) A Typology of Australian Tourism Based Condominiums. International Journal of Contemporary Hospitality Management.

Cassidy, K., \& Guilding, C. (2007). An exploratory investigation of tourist accommodation price setting in Australian strata titled properties. International Journal of Hospitality Management, 26, 277-292.

Cassidy, K. \& Guilding, C. (2010) Defining an emerging tourism industry sub-sector: Who are the strata titled tourism accommodation stakeholders? International Journal of Hospitality Management, 29, 421-431.

Crotts, J.C., \& Ragatz, R.L., (2002). Recent US timeshare purchasers: who are they, what are they buying, and how can they be reached? International Journal of Hospitality Management. 21 (3), 227-238.

Easthope, H \& Randolph, B. (2009) Governing the Compact City: The Challenges of Apartment Living in Sydney, Australia. Housing Studies, 24(2), 243-259.

Eisenhardt, K. (1985). Control: Organizational and economic approaches. Management Science, 31, 134-149.

Eisenhardt, K. (1988). Agency and institutional-theory explanations: The case of retail sales compensation. Academy of Management Journal, 31, 488-511. 
Eisenhardt, K. (1989). Agency theory: An assessment and review. Academy of Management Review, 14(1), 57-74.

Everton-Moore, K., Ardill, A., Guilding, C. \& J. Warnken, (2006) The Law of Strata Title in Australia: A Jurisdictional Stocktake. Australian Property Law Journal, 13, 1-35.

Exeter, M. (2009) "Planning for Effective Strata Titled Tourist Accommodation" paper presented at the Strata and Community Title in Australia for the $21^{\text {st }}$ Century 2009 conference.

Guilding, C., Warnken, J., Ardill, A., \& Fredline, L. (2005). An agency theory perspective on the owner/manager relationship in tourism-based condominiums. Tourism Management, 26 (3), 409-420.

Herman, E.S. (1981). Corporate control, corporate power. New York: Cambridge University Press.

Jensen, M.C., \& Meckling, W.H. (1976). Theory of the firm: managerial behavior, agency costs and ownership structure. Journal of Financial Economics, 3, 305-360.

Johns, N., and P. Lynch, (2007). The self-catering accommodation market: A review of electronic and other resources. International Journal of Hospitality Management, 26: 293-309.

Kakabadse, A. and Kakabadse, N., (2001). The Geopolitics of Governance, Hampshire: Palgrave.

Keltner, D., Gruenfeld, D. H., \& Anderson, C. (2003). Power, approach, and inhibition. Psychological Review, 110, 265-284.

Kesner, I. F., Shapiro, D.L., \& Sharma, A. (1994). Brokering mergers: An agency theory perspective on the role of representatives. Academy of Management Journal, 27(3), 703721.

Kosnik, R.D. (1987). Greenmail: A study of board performance in corporate governance. Administrative Science Quarterly, 32 (2), 163-185.

Lambert, R. A. (2001). Contracting theory and accounting. Journal of Accounting and Economics, 32, 3-87.

Lawton, L.J., Weaver, D. \& Faulkner, B. (1998). Customer satisfaction in the Australian timeshare industry. Journal of Travel Research, 37 (1), 30-38.

Letza, S., Sun, X., \& Kirkbride, J. (2004). Shareholding versus stakeholding: a critical view of corporate governance. Corporate Governance: An International Review, 12 (3), 242-262.

Lofland, J. (1974). Styles of reporting qualitative field research. American Sociologist, 9, 101-11. 
Marshall,C., \& Rossman, G. (1999). Designing Qualitative Research. Thousand Oaks, CA: Sage.

McLaughlin,R.M. (1990). Investment banking contracts in tender offers. Journal of Financial Economics, 28, 209-232.

Merriam, S. (1988). Case study research in education: a qualitative approach. San Francisco: Jossey-Bass.

Miles, M., \& Huberman, A. (1994). Qualitative Data Analysis: An Expanded Sourcebook. Thousand Oaks, CA: Sage.

Mills, P. K., (1990). On the quality of services in encounters: An agency perspective. Journal of Business Research, 20, 31-41.

Mizruchi, M. S., \& Yoo, M. (2002). Interorganizational power and dependence. In J. Baum (Ed.), Companion to organizations. Padstow, GB: Blackwell Business.

Pizam, A. (2006). Condominium hotels: A scorching hot lodging product. International Journal of Hospitality Management , 25 (2), 167-169.

Ragatz, R.L. \& Crotts, J.C., (2000). U.S. timeshare purchasers: who are they and why do they buy? Journal of Hospitality \& Tourism Research, 24 (1), 49-66.

Ross, M. (1973). The economic theory of agency: The principal's problem. American Economic Review, 63(2), 134-139.

Schatzman, L., \& Strauss, A. (1973). Field Research. Englewood Cliffs, NJ: Prentice Hall.

Sharma, A. (1997). Professional as agent: Knowledge asymmetry in agency exchange. The Academy of Management Review, 22 (3), 758-798.

Sparks, B., Butcher, K. \& Bradley., G. (2008). Dimensions and correlates of consumer value: An application to the timeshare industry. International Journal of Hospitality Management 27, 98-108.

Stoney, C. and Winstanley, D., (2001). Stakeholding: confusion or utopia? Mapping the conceptual terrain, Journal of Management Studies, 38(5): 603-26.

Upchurch, R.S. (2000). A glimpse at US consumer's interest in timesharing, inter product design evolution in the vacation ownership industry: from fixed weeks to points and vacation clubs. International Journal of Hospitality Management, 19, (4), 433-443.

Upchurch, R.S. (2002). Product design evolution in the vacation ownership industry: from fixed weeks to points and vacation clubs. Journal of Leisure Property, 2 (3), 239253.

Upchurch, R.S. \& Gruber, K., (2002). The evolution of a sleeping giant: resort timesharing. International Journal of Hospitality Management, 21, (3), 211-225. 
Warnken, J., \& Guilding, C. (2009). Multi-ownership of tourism accommodation complexes: A critique of types, relative merits, and challenges arising. Tourism Management, 30, 704-714.

Warnken, J., Guilding C., \& Cassidy, K. (2008) A Review of the Nature and Growth of Multi-titled Tourism Accommodation Complexes, International Journal of Hospitality Management, 27, 574-583.

Warnken, J., Russell, R., \& Faulkner, B. (2003). Condominium developments in maturing destinations: potentials and problems of long-term sustainability. Tourism Management, 24, 155-168. 
Table 1

Overview of Industry Experts

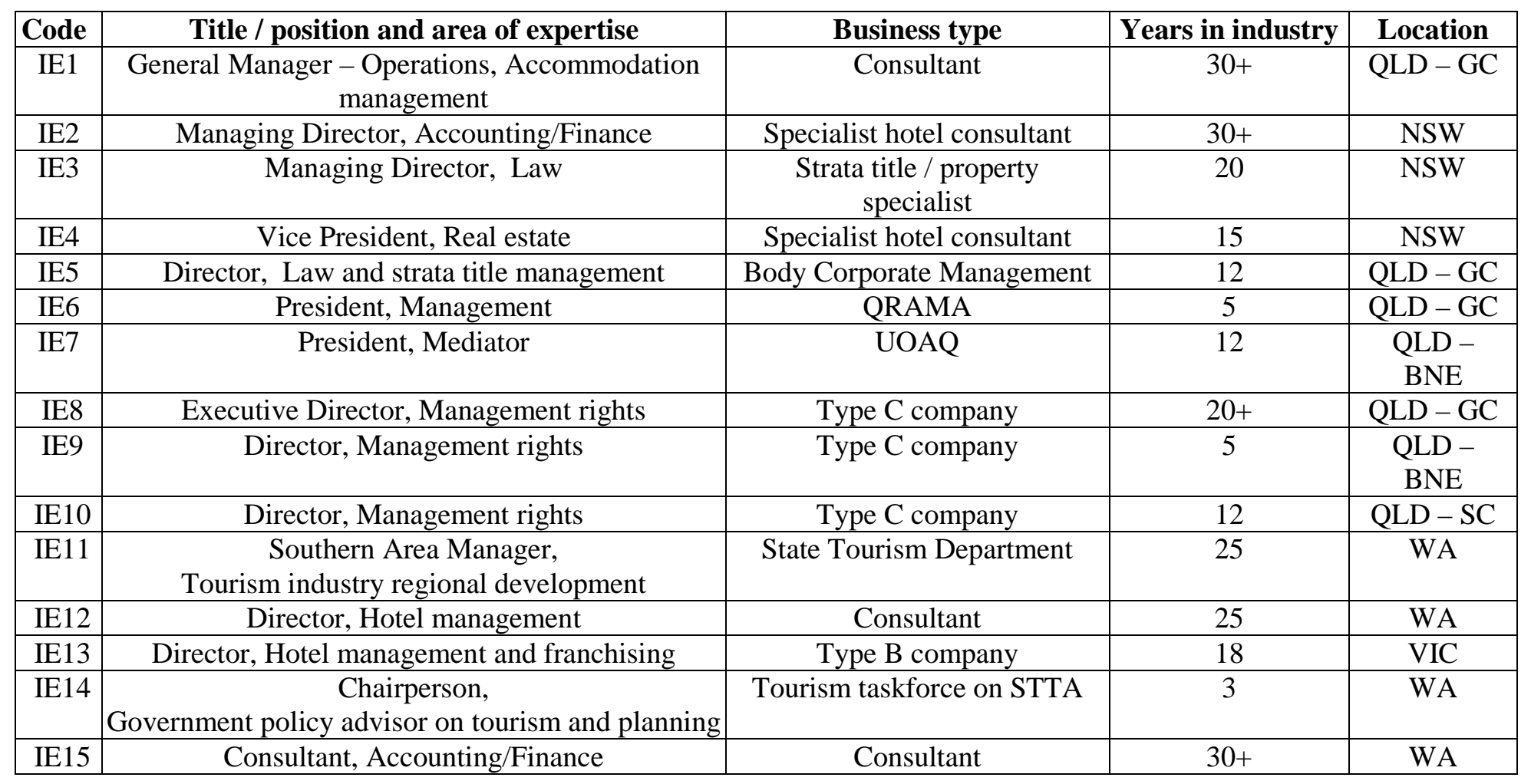

Legend

QLD - SC / GC / BNE: Queensland - Sunshine Coast, Gold Coast or Brisbane

QRAMA: Queensland Resident Accommodation Managers Association

UOAQ: $\quad$ Unit Owners Association of Queensland 
Table 2

Overview of Owners

\begin{tabular}{|c|c|c|c|c|c|c|c|c|}
\hline Owner & $\begin{array}{c}\text { Type of } \\
\text { management }\end{array}$ & Sex & $\begin{array}{l}\text { Location of } \\
\text { owner }\end{array}$ & $\begin{array}{l}\text { Location } \\
\text { of unit }\end{array}$ & $\begin{array}{l}\text { Regional/CBD } \\
\text { location }\end{array}$ & Size of unit & $\begin{array}{l}\text { Total units in } \\
\text { complex }\end{array}$ & $\begin{array}{c}\text { Length of current ownership } \\
\text { (years) }\end{array}$ \\
\hline $\mathrm{O} 1$ & $\mathrm{~A}$ & $\mathrm{~F}$ & NSW & QLD & $\mathrm{R}$ & 2BR & 65 & 5 \\
\hline $\mathrm{O} 2 *$ & A & $\mathrm{M}$ & QLD & QLD & $\mathrm{R}$ & $\begin{array}{l}1 \mathrm{X} 1 \mathrm{BR}, \\
2 \mathrm{X} 2 \mathrm{BR}\end{array}$ & 135 & 12,20 \\
\hline O3* & $\mathrm{A}$ & $\mathrm{M}$ & QLD & QLD & $\mathrm{R}$ & $\begin{array}{l}1 \mathrm{X} 2 \mathrm{BR}, \\
1 \mathrm{X} 3 \mathrm{BR}\end{array}$ & 17,70 & 10,5 \\
\hline $\mathrm{O} 4$ & B & $\mathrm{M}$ & NSW & QLD & $\mathrm{C}$ & $1 \mathrm{BR}$ & 180 & 5 \\
\hline $\mathrm{O} 5$ & $\mathrm{~B}$ & $\mathrm{~F}$ & NSW & QLD & $\mathrm{C}$ & 1BR & 128 & 15 \\
\hline O6* & B & $\mathrm{F}$ & QLD & QLD & $\mathrm{R}$ & $\begin{array}{l}1 \mathrm{X} 1 \mathrm{BR}, \\
1 \mathrm{X} 2 \mathrm{BR} \\
\end{array}$ & 18 & 3,6 \\
\hline O7 & $\mathrm{C}$ & $\mathrm{M}$ & NSW & QLD & $\mathrm{R}$ & $1 \mathrm{BR}$ & 150 & 3 \\
\hline O8 & $\mathrm{C}$ & $\mathrm{F}$ & QLD & QLD & $\mathrm{R}$ & $2 \mathrm{X} 1 \mathrm{BR}$ & Unknown & 1 \\
\hline O9 & $\mathrm{C}$ & $\mathrm{F}$ & QLD & QLD & $\mathrm{R}$ & 2BR & 52 & 7 \\
\hline $\mathrm{O} 10$ & $\mathrm{C}$ & $\mathrm{F}$ & QLD & QLD & $\mathrm{R}$ & 2BR & 98 & 4 \\
\hline
\end{tabular}

*: $\quad$ Multiple unit owner 
Table 3

Overview of Managers

\begin{tabular}{|c|c|c|c|c|c|c|c|c|}
\hline Complex & $\begin{array}{c}\text { Type of } \\
\text { management }\end{array}$ & $\begin{array}{c}\text { Location of } \\
\text { complex }\end{array}$ & $\begin{array}{l}\text { Total units } \\
\text { in complex }\end{array}$ & $\begin{array}{c}\text { Units in } \\
\text { letting pool }\end{array}$ & $\begin{array}{c}\% \text { in } \\
\text { letting pool }\end{array}$ & $\begin{array}{c}\text { Length of } \\
\text { management } \\
\text { (years at } \\
\text { current } \\
\text { complex) }\end{array}$ & $\begin{array}{c}\text { Length of } \\
\text { management at } \\
\text { other } \\
\text { complexes }\end{array}$ & $\begin{array}{c}\text { Nature of } \\
\text { business } \\
\text { engagement }\end{array}$ \\
\hline M1 & A & QLD R & 49 & 48 & 98 & 4 & 1.5 & Family business \\
\hline M2 & A & NSW R & 12 & 11 & 91 & 2.5 & N/A & HWT \\
\hline M3 & $\mathrm{A}$ & QLD R & 41 & 31 & 76 & 2 & N/A & HWT \\
\hline M4 & $\mathrm{B}$ & VIC C & 175 & 120 & 69 & 4 & 2 & Employee \\
\hline M5 & $\mathrm{B}$ & ACT C & 130 & 40 & 30 & 4 & 2 & Employee \\
\hline M6 & $\mathrm{B}$ & WA R & 150 & 150 & 100 & 1.5 & 5 & Employee \\
\hline M7 & $\mathrm{B}$ & WA C & 140 & 140 & 100 & 1.5 & 7.5 & Employee \\
\hline M8 & $\mathrm{C}$ & WA R & 220 & 165 & 75 & 1 & 12 & HWT \\
\hline M9 & $\mathrm{C}$ & WA R & 58 & 54 & 93 & 1 & 10 & Employee \\
\hline M10 & $\mathrm{C}$ & NSW C & 157 & 157 & 100 & 1 & 2.5 & Employee \\
\hline
\end{tabular}

\section{Legend}

\begin{tabular}{|l|l|}
\hline Location & State with R (regional) or C (CBD) location \\
\hline HWT & Husband and wife team. \\
\hline Total units in complex & If more than one property, an average is given. \\
\hline Length of management & N/A - no previous accommodation management experience. \\
\hline
\end{tabular}


TABLE 4

Summary of extent of agency challenges arising in different forms of STTA delivery

\begin{tabular}{|l|c|c|c|}
\hline $\begin{array}{l}\text { Agent effort } \\
\text { aversion }\end{array}$ & Type A & Type B & Type C \\
\hline $\begin{array}{l}\text { Agent diversion of } \\
\text { resources }\end{array}$ & High & Medium & Medium \\
\hline $\begin{array}{l}\text { Differential time } \\
\text { horizon }\end{array}$ & High & Medium & Medium \\
\hline $\begin{array}{l}\text { Differential attitude } \\
\text { to risk }\end{array}$ & $\begin{array}{c}\text { High agent risk } \\
\text { aversity }\end{array}$ & $\begin{array}{c}\text { Conventional agent } \\
\text { risk aversity }\end{array}$ & $\begin{array}{c}\text { Conventional agent } \\
\text { risk aversity }\end{array}$ \\
\hline
\end{tabular}


